\title{
OCORRÊNCIA DE Staphylococcus aureus EM CARCAÇAS DE FRANGO
}

\author{
MANUELA FIGUEIROA LYRA DE FREITAS * \\ ANA EMÍLIA DUARTE DE SOUZA LEÃO ** \\ TÂNIA LÚCIA MONTENEGRO STAMFORD *** \\ RINALDO APARECIDO MOTA ****
}

O objetivo deste trabalho foi avaliar as condições microbiológicas de carcaças de frango com relação às contagens de $S$. aureus. Foram analisadas 30 carcaças de frango in natura, e 31 carcaças de frango resfriadas, adquiridas em mercados públicos e supermercados, respectivamente. Em 58 (91,1\%) amostras foram isolados estafilococos, sendo que 40 $(65,0 \%)$ apresentaram S. aureus e $18(31,0 \%)$ Staphylococcus coagulase negativa (SCN). As contagens de $S$. aureus e SCN variaram entre 10 a $10^{6}$ $\mathrm{UFC} / \mathrm{g}$ de carne de frango. As carcaças de frango resfriadas apresentaram contagens inferiores de $S$. aureus em relação às carcaças de frango in natura, havendo correlação direta entre a temperatura de comercialização do produto e as contagens dessa bactéria. Foram confirmadas 78 (87,6\%) colônias típicas e $48(40 \%)$ colônias atípicas de S. aureus em Agar Baird-Parker. Conclui-se que padrões microbiológicos para Staphylococcus aureus em carcaças de frango in natura e resfriadas precisam ser adotados para a obtenção de produtos de boa qualidade para o consumidor e que as colônias atípicas de $S$. aureus em Agar Baird-Parker devem ser consideradas pelos analistas de alimentos.

PALAVRAS-CHAVES: AVES-CONTAMINAÇÃO; Staphylococcus aureus.

* Médica Veterinária, Doutoranda, Departamento de Nutrição da Universidade Federal de Pernambuco (UFPE). Espinheiro, Recife, PE (e-mail: manuelaflf@uol.com.br).

** Médica Veterinária Autônoma (e-mail: emiliaduarte@uol.com.br).

*** Professora, Adjunta, Departamento de Nutrição, UFPE, Cidade Universitária, Recife, PE (e-mail: newtonps@fastmodem.com.br).

**** Professor Adjunto, Departamento de Medicina Veterinária, Universidade Federal Rural de Pernambuco, Dois Irmãos, Recife, PE (e-mail: rinaldomota@bol.com.br). 


\section{INTRODUÇÃO}

A comercialização de frangos no Brasil sofreu profundas modificações nos últimos anos, quer em decorrência da elevação dos preços de outras fontes de proteína animal, quer como conseqüência da alteração de hábitos alimentares (HOFFMAM et al., 1999). Tratando-se de uma das principais fontes de proteína, o produto deve ser de boa qualidade e seguro para o consumidor.

A contaminação de carcaças de frango tem importantes implicações para a segurança e o tempo de prateleira do produto (CAPITA et al., 2001). Os microrganismos dos produtos de origem animal procedem de sua flora superficial, de suas vias respiratórias e do tubo gastrintestinal. A pele de muitos animais produtores de carne pode conter microrganismos como Micrococcus, Staphylococcus e Streptococcus beta-hemolíticos (FRAIZER e WESTHOFF, 2000).

Diferentes microrganismos têm sido isolados em carne de frango, como Escherichia coli (ABU-RUWAIDA et al., 1994;), Pseudomonas sp (OLIVIER, VEARY e HAY, 1996; HANG' OMBE et al., 1999; CAPITA et al., 2001), Staphylococcus aureus (ABU-RUWAIDA et al., 1994; OLIVIER, VEARY e HAY, 1996; ABD EL-MONEM e SAAD, 1999; CAPITA et al., 2001), Klebsiella sp (HANG' OMBE et al., 1999), Salmonella sp (ABU-RUWAIDA et al., 1994; HANG' OMBE et al., 1999), Citrobactersp (OLIVIER et al., 1996), Micrococcus sp (OLIVIER et al., 1996; HANG' OMBE et al., 1999; CAPITA et al., 2001), Streptococcus sp (HANG' OMBE et al., 1999), Bacillus sp (HANG' OMBE et al., 1999) e Campylobactersp (ABU-RUWAIDA et al., 1994).

$\mathrm{Na}$ microbiologia de alimentos, Staphylococcus aureus merece destaque pela sua freqüência e devido às intoxicações alimentares causadas pelo consumo de alimentos contendo enterotoxinas termoestáveis. De acordo com BERGDOLL (1999), as enterotoxinas estafilocócicas são proteínas de baixo peso molecular que varia de 27000 a 29000 daltons. São classificadas sorologicamente em SEA, SEB, SEC,$_{1}$ SEC $_{2}$, SEC $_{3}$, SED, SEE, SEG, SEH, SEI e SEJ (CARMO et al., 2002). Novas enterotoxinas estão sendo estudadas como SEK (ORWIN et al., 2001), SEL (ORWIN et al., 2003), SEM, SEN, SEO (JAURRAD et al., 2001; LOIR, BARON e GAUTIER, 2003) e SEU (LETERTRE et al., 2003). 
A carne de frango (com elevado teor protéico) tem sido implicada em vários casos de intoxicação alimentar, inclusive por Staphylococcus aureus (SHIOZAWA, KATO e SHIMIZU, 1980; ABU-RUWAIDA et al., 1994; BEAN e GRIFFIN, 1990).

Os produtos cárneos são considerados de qualidade microbiológica aceitável quando atendem critérios determinados pela legislação vigente. A Portaria $n^{0} 451 / 97$ do Ministério da Saúde (BRASIL, 1997) estabelecia como norma para carne de aves a ausência de Salmonella em vinte e cinco gramas do produto. Tal Portaria foi revogada pela Resolução no 12/0, da Agência Nacional de Vigilância Sanitária (BRASIL, 2001), que determina apenas a contagem de coliformes a 45드, não considerando microrganismos importantes como Salmonella e Staphylococcus aureus.

A presente investigação objetivou avaliar os níveis de contaminação de $S$. aureus em carcaças de frango comercializadas na cidade do Recife de acordo com a legislação para carnes e produtos cárneos.

\section{MATERIAL E MÉTODOS}

Foram analisadas sessenta e uma carcaças de frango no período compreendido entre outubro de 2001 a abril de 2002. Trinta amostras in natura (comercializadas em temperatura ambiente), sem marca, foram adquiridas em seis mercados públicos e trinta e uma amostras resfriadas, de cinco marcas, em sete supermercados da cidade de Recife (Pernambuco).

As carcaças de frango foram adquiridas em suas embalagens originais, colocadas em caixas isotérmicas contendo gelo reciclável, envoltas em sacos plásticos e enviadas ao Laboratório de Doenças InfectoContagiosas da Universidade Federal Rural de Pernambuco (UFRPE). No laboratório, as embalagens externas foram desinfetadas com solução de álcool iodado a 5\% para posterior abertura e retirada das amostras.

Fragmentos de pele e músculo foram coletados assepticamente e pesados até constituírem amostra de $25 \mathrm{~g}$. Foram preparadas quatro diluições, utilizando-se solução salina peptonada $0,1 \%$ como diluente. 
Preparou-se a primeira diluição pela adição de $25 \mathrm{~g}$ da amostra em $225 \mathrm{~mL}$ do diluente, seguida de homogeneização por um minuto com auxílio de aparelho elétrico (handmix Wallita ${ }^{\circledR}$ ) em baixa rotação. Para o preparo da segunda diluição transferiu-se $1 \mathrm{~mL}$ da diluição inicial para tubo de ensaio estéril, contendo $9 \mathrm{~mL}$ do mesmo diluente e assim sucessivamente até a quarta diluição.

Alíquotas de 0,1 mL (retiradas de cada diluição) foram semeadas em meio de cultura Baird-Parker (MERCK ${ }^{\circledR}$ ) enriquecido com emulsão de gema de ovo em solução salina 0,85\% (1:1) e solução de telurito de potássio (1\%). Após espalhamento na placa, com auxílio de alça de Drigalsky, as placas foram incubadas a $37^{\circ} \mathrm{C}$ por $24-48$ horas para posterior contagem das colônias típicas e atípicas (AOAC, 1995).

Três colônias típicas e três atípicas da mesma diluição foram transferidas para caldo $\mathrm{BHI}$ (DIFCO®), que foi incubado por 24 horas a $37^{\circ} \mathrm{C}$. A semeadura ocorreu em placas contendo Ágar Base (OXOID®), acrescido de $8 \%$ de sangue ovino desfibrinado, nas quais foram observadas as características de crescimento das colônias, produção de hemólise, pigmento e características morfo-tintoriais pelo método de coloração de Gram.

Para a identificação do Staphylococcus aureus, todas as cepas de estafilococos foram submetidas aos testes de produção de coagulase livre (Plasma Coagulase EDTA, Coagu-Plasma LB - Laborclin, Brasil), termonuclease (Tnase - Ágar Azul de Orto-toluidina-DNA) e catalase (SILVA, 1997). As provas de produção de acetoína, fermentação da glicose (anaerobiose) e do manitol (aerobiose e anaerobiose) foram realizadas de acordo com MAC FADDIN (1980), sendo os isolados classificados conforme BAIRD-PARKER (1990).

A análise estatística dos dados foi realizada segundo CONOVER (1980) utilizando-se o programa Statistical Analysis System na versão 6.12 (SAS, 1996). Adotou-se o nível de significância ou margem de erro nas decisões dos testes estatísticos de $5 \%$.

\section{RESULTADOS E DISCUSSÃO}

Foram constatadas $58(91,1 \%)$ carcaças de frango positivas para 
estafilococos, sendo que $40(65,0 \%)$ apresentaram S. aureus e 18 $(31,0 \%)$ Staphylococcus coagulase negativa (Tabela 1).

\section{TABELA1-CONTAGEM DE S. aureus E Staphylococcus COAGULASE NEGATIVA ISOLADOS DE CARCAÇAS DE FRANGO COMERCIALIZADAS NA CIDADE DO RECIFE-PE, 2002}

\begin{tabular}{|c|c|c|c|}
\hline \multicolumn{4}{|c|}{ Temperatura de Comercializa $\stackrel{a}{a}$} \\
\hline \multicolumn{2}{|c|}{ In natura } & \multicolumn{2}{|c|}{ Resfriada ${ }^{(1)}$} \\
\hline Amostra & $\begin{array}{l}\text { Contagem } \\
\text { (UFC/g) }\end{array}$ & Amostra & $\begin{array}{l}\text { Contagem } \\
\text { (UFC/g) }\end{array}$ \\
\hline 01 & $5,0 \times 10^{1 *}$ & 01 & $1,0 \times 10^{4 *}$ \\
\hline 02 & $2,0 \times 10^{4}$ * & 02 & $1,0 \times 10^{2}$ * \\
\hline 03 & $1,0 \times 10^{4 *}$ & 03 & $2,5 \times 10^{3 *}$ \\
\hline 04 & $1,3 \times 10^{6 *}$ & 04 & $7,6 \times 10^{3 *}$ \\
\hline 05 & $5,8 \times 10^{5 *}$ & 05 & $1,8 \times 10^{3}$ * \\
\hline 06 & $1,9 \times 10^{5 *}$ & 06 & $8,6 \times 10^{3}$ * \\
\hline 07 & $6,8 \times 10^{4 *}$ & 07 & $3,2 \times 10^{3}$ * \\
\hline 08 & $6,3 \times 10^{4 *}$ & 08 & $3,7 \times 10^{3 *}$ \\
\hline 09 & $2,1 \times 10^{5 *}$ & 09 & $4,9 \times 10^{3 *}$ \\
\hline 10 & $1,6 \times 10^{2}$ * & 10 & $2,7 \times 10^{3 *}$ \\
\hline 11 & $1,0 \times 10^{2 *}$ & 11 & $7,3 \times 10^{3 *}$ \\
\hline 12 & $2,0 \times 10^{4}$ * & 12 & $3,0 \times 10^{3}$ * \\
\hline 13 & $7,0 \times 10^{4 *}$ & 13 & $1,0 \times 10^{2 *}$ \\
\hline 14 & $9,0 \times 10^{3}$ * & 14 & $2,4 \times 10^{3}$ * \\
\hline 15 & $1,2 \times 10^{5 *}$ & 15 & $1,9 \times 10^{4 *}$ \\
\hline 16 & $5,7 \times 10^{4 *}$ & 16 & $3,0 \times 10^{3 * *}$ \\
\hline 17 & $4,0 \times 10^{3 *}$ & 17 & $3,0 \times 10^{3 * *}$ \\
\hline 18 & $8,2 \times 10^{4 *}$ & 18 & $1,2 \times 10^{4 * *}$ \\
\hline 19 & $5,3 \times 10^{3}$ * & 19 & $6,3 \times 10^{4 * *}$ \\
\hline 20 & $7,0 \times 10^{1 *}$ & 20 & $4,3 \times 10^{3 * *}$ \\
\hline 21 & $3,0 \times 10^{3}$ * & 21 & $2,3 \times 10^{2 * *}$ \\
\hline 22 & $1,6 \times 10^{3 *}$ & 22 & $1,9 \times 10^{4 * *}$ \\
\hline 23 & $4,7 \times 10^{3}$ * & 23 & $2,3 \times 10^{2 * *}$ \\
\hline 24 & $2,0 \times 10^{3 *}$ & 24 & $3,2 \times 10^{3 * *}$ \\
\hline 25 & $6,0 \times 10^{3 *}$ & 25 & $1,2 \times 10^{4 * *}$ \\
\hline 26 & $1,9 \times 10^{5 * *}$ & 26 & $4,3 \times 10^{3 * *}$ \\
\hline 27 & $1,2 \times 10^{5 * *}$ & 27 & $3,4 \times 10^{3 * *}$ \\
\hline 28 & $2,6 \times 10^{5 * *}$ & 28 & $5,2 \times 10^{4 * *}$ \\
\hline 29 & $3,3 \times 10^{5 * *}$ & & \\
\hline 30 & $6,9 \times 10^{3 * *}$ & & \\
\hline
\end{tabular}

(1) Em três amostras resfriadas não foi registrada a presença de Staphylococcus spp. *Staphylococcus aureus (coagulase positiva); ** Staphylococcus spp (coagulase negativa). 
Observou-se elevado percentual de $S$. aureus em carcaças de frango, corroborando os achados de OLIVIER, VEARY e HOLY (1996). Tais autores analisaram carcaças de frango de planta de processamento não-automática na África e isolaram $S$. aureus em todas as amostras. Já HANG'OMBE et al. (1999) obtiveram baixo percentual de isolamento, analisando carcaças de frango comercializadas na Zâmbia, provavelmente pelo fato de não terem utilizado meio de cultura seletivo para estafilococos.

As contagens de $S$. aureus em carcaças resfriadas variaram entre 10 e $10^{4} \mathrm{UFC} / \mathrm{g}$, aproximando-se dos achados de VIEIRA e TEIXEIRA (1997) que verificaram condições higiênico-sanitárias inadequadas de carcaças de frango resfriadas procedentes de Minas Gerais.

Calculou-se a média das contagens de Staphylococcus aureus em logaritmo (log10 UFC/g), visando facilitar a comparação dos resultados obtidos neste estudo com o de outros autores. Obteve-se média de 4,1 $\log 10$ UFC/g para as carcaças de frango in natura e de 3,4 log 10 UFC/g para as carcaças de frango resfriadas. Resultados semelhantes foram encontrados por ABU-RUWAIDA et al. (1994) que obtiveram níveis de 2,7 a 4,1 log10 UFC/g. Tais médias não são desejáveis, pois podem estar associadas com a produção de enterotoxinas termoestáveis responsáveis por diversas intoxicações alimentares por S. aureus. ABD EI-MONEM e SAAD (1999) verificaram contagens de $S$. aureus variando entre 2,26 a $4,13 \log 10 \mathrm{UFC} / \mathrm{cm}^{2}$ em 110 carcaças de frango analisadas em várias etapas do processamento em abatedouro no Egito. CAPITA et al. (2001) constataram média de 3,67 $\log 10 \mathrm{UFC} / \mathrm{g}$ de $S$. aureus em 40 carcaças de frango resfriadas, adquiridas em três supermercados e dois mercados populares na Espanha.

Considerando a distribuição das amostras com relação à potência das contagens de $S$. aureus na base de dez (Tabela 2), o percentual de amostras com potências de $10^{4}$ a $10^{6} \mathrm{UFC} / \mathrm{g}$ foi mais elevado entre as carcaças de frango in natura (comercializadas em mercados públicos) que entre as resfriadas (vendidas em supermercados). Verificou-se diferença significativa entre as duas condições de temperatura de comercialização (in natura e resfriada) e o grau da potência ao nível de significância de $\mathrm{P}<0,05$. 


\section{TABELA 2 - CORRELAÇÃO ENTRE AS CONTAGENS DE S. aureus E A TEMPERATURA DE COMERCIALIZAÇÃO DAS CARCAÇAS DE FRANGO IN NATURA E RESFRIADA}

\begin{tabular}{|c|c|c|c|c|c|c|c|}
\hline \multirow{3}{*}{$\begin{array}{l}\text { Contagem } \\
\text { (UFC/g) }\end{array}$} & \multicolumn{4}{|c|}{ Temperatura } & \multirow{2}{*}{\multicolumn{2}{|c|}{ Grupo total }} & \multirow{3}{*}{$\begin{array}{c}\text { Estat stica e } \\
\text { valor de P }\end{array}$} \\
\hline & \multicolumn{2}{|c|}{ In natura } & \multicolumn{2}{|c|}{ Resfriada } & & & \\
\hline & N" & $\%$ & N" & $\%$ & N" & $\%$ & \\
\hline $10^{1}$ a $10^{3}$ & 12 & 48,0 & 13 & 86,7 & 25 & 62,5 & $\chi^{2}=5,980$ \\
\hline $10^{4}$ a $10^{6}$ & 13 & 52,0 & 2 & 13,3 & 15 & 37,5 & $P=0,014^{*}$ \\
\hline Total & 25 & 100,0 & 15 & 100,0 & 40 & 100,0 & \\
\hline
\end{tabular}

* Diferença significativa ao nível de 5,0\%.

YASHODA et al. (2000) e CAPITA et al. (2001) também observaram maiores contagens de $S$. aureus em carcaças de frango abatidas artesanalmente e vendidas em feiras e mercados públicos do que nas processadas em abatedouros industriais e comercializadas em supermercados.

O maior número de amostras com contagens de $10^{4}$ a $10^{6} \mathrm{UFC} / \mathrm{g}$ de $S$. aureus em carcaças de frango in natura pode ser explicado pelas precárias condições higiênicas das carcaças oferecidas ao consumidor. O manuseio direto do produto em mercados públicos contribui para o acréscimo nas contagens de $S$. aureus. Esse microrganismo está presente nas mãos, pele e fossas nasais do homem e nem sempre os manipuladores cultivam hábitos higiênicos adequados. Ao contrário, as carcaças de frango resfriadas são vendidas em supermercados, abatidas industrialmente sob Inspeção Estadual ou Federal, havendo maior exigência no que diz respeito à higiene.

Também realizou-se análise confirmatória para $S$. aureus coagulase positiva, considerando a classificação das colônias de estafilococos isoladas em Agar Baird-Parker em colônias típicas e atípicas (Tabela 3). Para BOARI et al. (2002) a presença de colônias atípicas pode levar o analista de alimentos a desconsiderá-las no processo de 
confirmação de $S$. aureus. Desta forma, o produto será classificado como apto para comercialização apesar de poder oferecer risco ao consumidor.

Das 209 colônias selecionadas, 89 (42,6\%) apresentaram características de colônias típicas e 120 (57,4\%) de colônias atípicas. Dentre essas colônias, 78 (87,6\%) típicas e 48 (40,0\%) atípicas foram confirmadas como $S$. aureus. A importância do isolamento de colônias atípicas de $S$. aureus foi ressaltada por outros autores. CAPITA et al. (2002), trabalhando com isolados de 96 amostras de carne de frango na Espanha, verificaram que 24 (25\%) das colônias isoladas em Agar Baird-Parker eram atípicas. BOARI et al. (2002) observaram a presença de cepas de estafilococos coagulase positiva formadoras de colônias atípicas em queijos maturados, comercializados na cidade de Lavras, Minas Gerais.

\section{TABELA 3 - PERCENTUAL DE COLÔNIAS TÍPICAS E ATÍPICAS DE S.aureus ISOLADAS DE AGAR BAIRD-PARKER}

\begin{tabular}{|c|c|c|c|c|c|c|c|}
\hline \multirow{3}{*}{ Col nias } & \multicolumn{4}{|c|}{ Staphylococcus aureus } & & & \\
\hline & \multicolumn{2}{|c|}{ Positivo } & \multicolumn{2}{|c|}{ Negativo } & \multicolumn{2}{|c|}{ TOTAL } & \multirow{2}{*}{$\begin{array}{c}\text { Estat stica } \\
\text { Valor de P }\end{array}$} \\
\hline & N" & $\%$ & N" & $\%$ & N" & $\%$ & \\
\hline T picas & 78 & 87,6 & 11 & 12,4 & 89 & 100,0 & $\chi^{2}=48,442$ \\
\hline & & & & & & & $P<0,001^{*}$ \\
\hline At picas & 48 & 40,0 & 72 & 60,0 & 120 & 100,0 & \\
\hline Grupo Total & 126 & 60,3 & 83 & 39,7 & 209 & 100,0 & \\
\hline
\end{tabular}

A Portaria n. 451/97 e a Resolução nº 12/2001 do Minsitério da Saúde (BRASIL, 1997 e 2001) estabelecem como padrão para S. aureus a contagem de $10^{3} \mathrm{UFC} / \mathrm{g}$ de carnes e produtos cárneos de forma geral. Considerando a temperatura de comercialização do produto e os 
resultados expressos na Tabela 4, 15 (24,6\%) amostras não se enquadraram no padrão com percentual mais elevado para as in natura $(43,3 \%)$ que para as resfriadas $2(6,4 \%)$. Verificou-se diferença significativa entre as duas condições de temperatura de comercialização em relação à contagem de $S$. aureus, indicando melhor conservação dos produtos resfriados. MANSO et al. (1987) estudaram 51 amostras de frango resfriado na Espanha e encontraram 22 (43,1\%) amostras com contagens acima do padrão permitido.

\section{TABELA 4 - ANÁLISE DAS CARCAÇAS DE FRANGO SEGUNDO O LIMITE MÁXIMO PARA ESTAFILOCOCOS COAGULASE POSITIVA (1030FC/g) ESTABELECIDO PELA PORTARIA № 451/97 E RESOLUÇÃO № 12/01 PARA CARNES E PRODUTOS CÁRNEOS}

\begin{tabular}{|c|c|c|c|c|c|c|c|}
\hline & \multicolumn{6}{|c|}{ Carca as de Frango } & \multirow{3}{*}{$\begin{array}{c}\text { Estat stica e } \\
\text { Valor de P }\end{array}$} \\
\hline & \multicolumn{2}{|c|}{ In natura } & \multicolumn{2}{|c|}{ Resfriada } & \multicolumn{2}{|c|}{ Grupo total } & \\
\hline & N" & $\%$ & N" & $\%$ & N" & $\%$ & \\
\hline Enquadradas no padr ${ }^{\mathrm{a}} \mathrm{o}$ & 8 & 26,7 & 18 & 58,1 & 26 & 42,6 & $\chi^{2}=12,100$ \\
\hline & & & & & & & $P=0,002^{*}$ \\
\hline No limite & 9 & 30,0 & 11 & 35,5 & 20 & 32,8 & \\
\hline$N^{\mathrm{a}} \mathrm{o}$ enquadradas no padr $\mathrm{a}^{\mathrm{a}} \mathrm{O}$ & 13 & 43,3 & 2 & 6,4 & 15 & 24,6 & \\
\hline Total & 30 & 100,0 & 31 & 100,0 & 61 & 100,0 & \\
\hline
\end{tabular}

* Diferença significativa ao nível de 5,0\%.

De acordo com CAPITA et al. (2001), o valor máximo para contagens de $S$. aureus enterotoxigênico em carcaças de frango na Espanha é de 2 log 10 UFC/g. Relataram ainda, que o Centro Nationale d'Etudes et de Recommendations sur la Nutrition et L'Alimentation (CNERNA CNRS) aplica o plano de amostragem de três classes para carne de frango ( $\mathrm{n}=5, \mathrm{c}=2, \mathrm{~m}=10^{3} \mathrm{UFC} / \mathrm{g}$ e $\mathrm{M}=10^{4} \mathrm{UFC} / \mathrm{g}$ ). O estado americano de Nebraska adota como referência para carne de frango a ausência de $S$. aureus coagulase positiva em um grama da amostra. 


\title{
4 CONCLUSÃO
}

Os resultados obtidos neste estudo permitem concluir que as carcaças de frango resfriadas apresentam contagens inferiores de $S$. aureus em relação às in natura. A má conservação do produto indica a necessidade de implantação de medidas de controle e higiene no processamento de carcaças de frango in natura para obtenção de produtos seguros. Sugere-se a criação de padrões microbiológicos para Staphylococcus aureus em carcaças de frango in natura e resfriadas para a obtenção de produtos de boa qualidade para 0 consumidor. Também é preciso que colônias atípicas de $S$. aureus em Ágar Baird-Parker sejam consideradas pelos analistas de alimentos.

\begin{abstract}
OCCURRENCE OF Staphylococcus aureus IN CHICKEN CARCASSES

The objective of this work was to evaluate the microbiological conditions of chicken carcasses, with regards to $S$. aureus count. Thirty carcasses of chicken in natura and 31 refrigerated carcasses of chicken acquired in public markets and supermarkets were analyzed, respectively. In $58(91.1 \%)$ of the samples, Staphylococcus sp. were isolated, from which $40(65.0 \%)$ presented Staphylococcus aureus and $18(31.0 \%)$ coagulase negative Staphylococcus (CNS). Staphylococcus aureus count and CNS varied between 10 to $10^{6} \mathrm{CFU} / \mathrm{g}$ of chicken meat. The refrigerated chicken carcasses presented lower counting of $S$. aureus in relation to carcasses of chicken in natura, showing a direct co-relation between the commercialization temperature of the product and the count of these bacteria. Seventy-eight $(87.6 \%)$ of typical colonies and $48(40 \%)$ atypical colonies of $S$. aureus were confirmed in Baird-Parker agar. It was concluded that the microbiological standards for $S$. aureus in chicken carcasses in natura and refrigerated needs to be adopted for the obtention of high quality products for the consumer and that the atypical colonies of $S$. aureus in Baird-Parker agar should be considered by food analysts.
\end{abstract}

KEY-WORDS: POULTRY-CONTAMINATION; Staphylococcus aureus

\section{REFERÊNCIAS}

1 ABD EL-MONEM, K. H. M.; SAAD, S. M. Contamination of dressed broilers with enterotoxigenic Staphylococcus aureus during processing. Veterinary Medical Journal, Giza, v. 47, n. 1, p. 1-10, 1999. 
2 ABU-RUWAIDA, W. N. et al. Microbiologycal quality of broilers during processing in a modern comercial slaughterhouse in Kuwait. Journal of Food Protection, Des Moines, v. 57, n.10, p. 887-892, 1994

3 AOAC. Association of Official Analytical Chemists. Official methods of analysis of AOAC International. $1^{\text {th }}$ ed. Arlington, 1995.

4 BAIRD-PARKER, A.C. The Staphylococci: an introduction. The Journal of Applied Bacteriololy, Oxford, v.19, p. 15-85, 1990.

5 BEAN, N. H.; GRIFFIN, P. M. Foodborne disease outbreaks in the United States, 1973-1987: pathogens, vehicles, and trends. Journal of Food Protection, Des Moines, v. 53, n. 9, p. 804-817, 1990.

6 BERGDOLL, M. S. Analytical methods for Staphylococcus aureus. International Journal of Food Microbiology, Amsterdam, v. 10, p.91-100, 1990.

7 BOARI, C. A. et al. Ocorrência de cepas de estafilococos coagulase positiva formadoras de colônias atípicas em ágar Baird-Parker em queijos maturados. Boletim do CEPPA, Curitiba, v. 20, n. 2, p. 347-354, 2002.

8 BRASIL. Ministério da Saúde. Portaria no 451 de 19 de setembro de 1997. Aprova o Regulamento Técnico princípios gerais para o estabelecimento de critérios e padrões microbiológicos para alimentos. Diário Oficial [da] República Federativa do Brasil. Brasília, DF, 22 set. 1997. Seção 1, p. 21005-21012.

9 BRASIL. Ministério da Saúde. Resolução RDC № 12, de 02 de janeiro de 2001. Aprova o Regulamento Técnico sobre padrões microbiológicos para alimentos. Diário Oficial [da] República Federativa do Brasil. Brasília, DF, 10 jan. 2001. Seção 1, p. 46-53.

10 CAPITA, R. et al. Microbiological quality of retail poultry carcasses in Spain. Journal of Food Protection, Des Moines, v. 64, n. 12, p. 1961-1966, 2001.

11 CAPITA, R. et al. Characterization of Staphylococcus aureus isolated from poultry meat in Spain. Poultry Science, Champaign, n. 81, p. 414-421, 2002.

12 CARMO, L. S. et al. Food poisoning due to enterotoxigenic strains of Staphylococcus present in minas cheese and raw milk in Brazil. Food Microbiology, London, v. 14, p. 9-14, 2002.

13 CONOVER, W. J. Practical nonparametric statistics. New York: John Wiley, 1980. 495 p.

14 FRAZIER, W. C.; WESTHOFF, D. C. Microbiología de los alimentos. 4. ed. Zaragoza: Acribia, 2000. 681p.

15 HANG'OMBE, B. M. et al. Isolation of bacteria during processing of chicken carcass for the market in Lusaka, Zambia. Veterinaski Arhiv, Zagreb, v. 69, 
n. 4, p. 191-197, 1999.

16 HOFFMANN, F. L. et al. Microbiologia de carcaças e carnes mecanicamente separadas obtidas de abatedouros de aves da região de São José de Rio Preto-São Paulo. In: CONGRESSO BRASILEIRO DE MICROBIOLOGIA, 20., 1999, Salvador. Anais... Salvador: [s. n.], 1999. p.345.

17 JAURRAD, S. et al. egc a highly prevalent operon of enterotoxin gene, forms a putative nursey of superantigens in Staphylococcus aureus. Journal of Immunology, Rockville Pike, v. 166, p. 669-677, 2001.

18 LETERTRE, C. et al. Identification of a new putative enterotoxin SEU encoded by egc cluster of Staphylococcus aureus. Journal of Applied Microbiological Research, Oxford, v. 2, p. 63-76, 2003.

19 LOIR, Y. L.; BARON, F.; GAUTIER, M. Staphylococcus aureus and Food Poisoning. Genetics and Molecular Research, v. 2, p. 63-76, 2003.

20 MAC FADDIN, J.F. Biochemical test for identification of medical bacteria. $2^{\text {nd }}$ ed. Baltimore: Williams \& Wilkins, 1980. $527 \mathrm{p}$.

21 MANSO, R. et al. Estudio bacteriológico de canales de pollo refrigeradas. Alimentaria, Madri, n. 185, p. 11-13, 1987.

22 OLIVIER, C. M. M.; VEARY, T.E.C.; HOLY, A.V. Microbiological status of selected chicken carcases from non-automated poultry processing plant. Journal of Basic Microbiology, Berlin, v. 36, n. 1, p. 41-49, 1996.

23 ORWIN, P. M. et al. Biochemical and biological properties of staphylococcal enterotoxin K. Infection and Immunity, Washington, v. 69, n. 1, p. 360-366, 2001.

24 ORWIN, P. M. et al. Characterization of Staphylococcus aureus enterotoxin L. Infection and Immunity, Washington, v. 71, n. 5, p. 2916-2919, 2003.

25 SAS Institute. Statistical system for windows: versão 6.12. Cary, 1996.

26 SHIOZAWA, K.; KATO, E.; SHIMIZU, A. Enterotoxigenicity of Staphylococcus aureus strains isolated from chickens. Journal of Food Protection, Des Moines, v. 43, n. 9, p. 683-685, 1980.

27 SILVA JÚNIOR., E. A. Manual de controle higiênico-sanitário em alimentos. São Paulo: Varela, 1997. 385 p.

28 VIEIRA, C. R. N.; TEIXEIRA, C. G. Condições higiênico-sanitárias de carcaças resfriadas de frango comercializadas em Poços de Caldas-MG. Revista Higiene Alimentar, São Paulo, v. 11, n. 48, p. 36-40, 1997.

29 YASHODA, K. P. et al. A reaserch note microbiological quality of broiler chicken carcasses processed hygienically in a small scale poultry processing unit. Journal of Food Quality, Westport, v. 24, p. 249-259, 2000. 